NASA Technical Memorandum 88847

\title{
The Space Station Power System
}

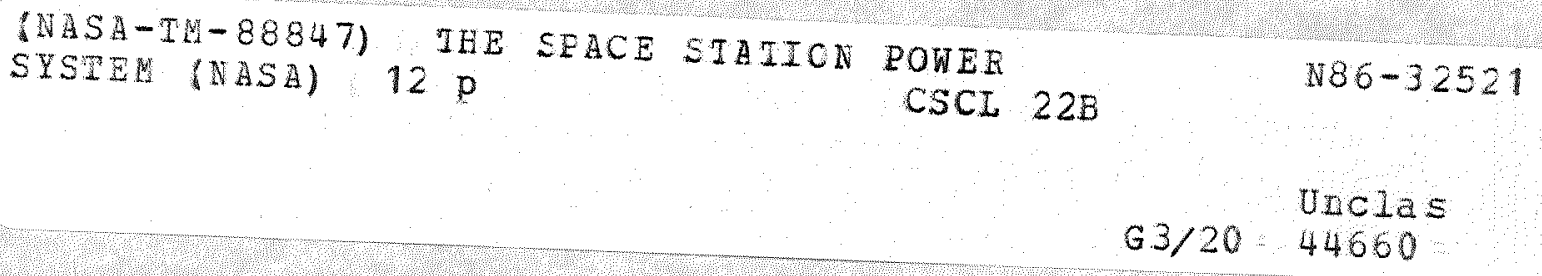

Cosmo R. Baraona

Lewis Research Center

Cleveland, Ohio

Prepared for the

Fifth Conference on Photovoltaic Generators in Space

sponsored by the European Space Agency

Noordwijk, Netherlands, September 30-October 4, 1986 
THE SPACE STATION POWER SYSTEM

Cosmo R. Baraona

National Aeronautics and Space Administration

Lewis Research Center

Clevel and, Ohio 44135

\section{ABSTRACT}

The manned Space Station is the next major NASA program. It presents many challenges to the power system designers. The power system in turn is a major driver on the overall configuration. In this paper, the major requirements and guidel ines that affect the station configuration and the power system are explained. The evolution of the Space Station power system from the NASA program develop$\hat{\sim}$ ment-feasibility phase through the current prelimi$\approx$ nary design phase is described. Several early $\dot{\omega}$ station concepts, both fanciful and feasible, are described and linked to the present concept. The recently completed Phase B trade study selections of photovoltaic system technologies are described in detail. A summary of the present solar dynamic and power management and distribution systems is also given for completeness.

Keywords: Photovoltaic, Solar Array, Power System, Spacecraft Power, Solar Cell, Batteries

\section{BACKGROUND}

The Space Station System is the next major step in the manned space program. The Space Station will be a multi-purpose facility which will enable advancements in science, technology, and space transportation capabilties. It will promote commercialization of space and open new avenues not yet fully realized.

Stations in space have been in the minds of writers, scientists, and engineers for decades. In a series of fictional articles beginning with the October 1869 issue of the "Atlantic Monthly," a fanciful space station was described by Rev. E.E. Hale from Boston. "The Brick Moon" articles describe a hollow sphere $200 \mathrm{ft}$ in diameter. It was whitewashed on the outside to serve as an aid to navigation. The moon was launched into orbit by waterwheels. The article makes no mention of a power source for the brick moon after it left the Earth. The brick moon concept was not soundly based by today's standards, but it was entertaining and thought provoking:

In 1928, Hermann Noordung published "Befahrung des Weltraums" (The Problem of Space Travel). He described a manned toroidal space station that rotated to produce artificial gravity (Fig. 1). The idea was further developed in the March 22, 1952 , issue of "Collier's" magazine and was described in a book, Across the Space Frontier (Viking Press, New York, NY 1952). The Walt Disney Studios produced television programs that were based on Noordung's concept. In this concept, power was produced by a large parabolic mirror which focused solar energy to heat steam and operate a turbine-generator. In today's terminology, this was a form of a solar thermal dynamic power system. At that time, practical photovoltaic (PV) cells had not yet been invented:

These early works, as well as numerous studies conducted in the 1960's and 1970's since the creation of NASA (Ref. 1), have helped establish a role for a manned space station. The solar dynamic power source described in 1952 was primitive, but functional. However, most unmanned satellites launched since the beginning of the space age in 1957 have: been powered by silicon solar cell based photovitaic systems. A few deep space interplanetary missions and manned spacecraft like Mercury, Gemini, and Apollo are the exception. During this $\mathrm{era}$, technology has been developed for photovoltaic, solar dynamic, and nuclear systems as well. The primary thrust of these developments has been toward lighter weight, lower volume, higher efficiencies, longer lifetimes and reliability. These technologies and flight experiences formed the starting point for establishing the feasibility for the current Space Station and for defining its. power system.

\section{FEASIBILITY PHASE}

The current Space Station program can trace its roots back to 1981, when Technology Steering Committees were formed to identify candidate technologies. These committees were staffed with people from the NASA field centers. In early 1982 , the Space Station Task Force was formed at NASA Headquarters in Washington, D.C., to determine the feasibility of a space station. This is referred to as Phase $A$ in the program development process.

In August 1982, the Task Force sponsored contracts with eight major aerospace companies to analyze the uses or missions for a manned space station. Specific missions to be performed were determined and studied extensively, but are too numerous to 
describe in detail here (Ref. 2). These missions included materials processing, earth and space observations, and servicing and repair of satellites and other payloads. These mission analys is studies showed that the Station would serve as an assembly facility, a storage depot, and a transportation node or way-station for payloads intended for higher Earth orbits or for interplanetary missions.

These diverse missions led to the Space Station Complex shown in Fig. 2. It is composed of a manned core and an unmanned co-orbiting platform both in a $28.5^{\circ}$ orbit. Another platform is in a polar orbit. A system of unmanned vehicles for maneuvering payloads near the Station or for transferring them to other orbits is part of the Space Station System.

The mission analysis studies identified resource requirements such as crew time, thermal control, power, etc., for each projected experimenter, each scientific and commercial user of space station. The sum of the power requirements of each of these missions defined the total requirement for each station element. Power levels were determined as a function of time from the Initial Operational Capability (IOC) through some future power level when the station and the number of missions has grown. These power requirements have changed as the mission definition has evolved. The current user power levels are shown in Table 1. User power or bus power is expressed in kilowatts electric (kWe) in Table 1 and elsewhere in this paper. User power means all system losses for generation, storage, conditioning, and distribution have been taken into account. Note that the Station IOC power of $75 \mathrm{kWe}$ is about an order of magnitude higher than Skylab. Skylab, the first U.S. manned space station launched in 1973 is the largest ( 8 kWe user power, 22 kWe array) solar power system flown in space to date. This $75 \mathrm{kWe}$ requirement for the planned Space Station is the most challenging factor facing the power system designer.

Additional challenges arise from programmatic requirements imposed on the power system designer (Table 2). These additional requirements are management and/or engineering related. They include cost (both initial and life-cycle), schedule, and technical-development risk, weight, and safety requirements as most large spacecraft projects do. However, the permanent nature of space station results in some new and unique requirements such as growth capability, maintainability, and commonality of hardware and software across ali station elements. Future replacement and growth of the station systems requires that they be designed so that they can accept future changes in technology (i.e., technology transparency) yet still provide the same functions. Other considerations are the Station orbit altitude and its decay, assembly and buildup, lifetime, and logistics and sparing.

In the spring of 1983, the Task Force was expanded to include a Concept Development Group (COG). This group took the results from the mission analysis studies, and with the help of all the NASA centers and many aerospace companies, synthesized them into several candidate space station configurations. They also further studied and sharpened technology selection for all the station systems including power. PV planar, PV concentrator, microwave power transmission, solar dynamic and nuclear systems were studied. The power tower or gravity gradient stabilized and many other confiqurations were studied as candidate station geometries. At this time, photovoltaics appeared to be the leading candidate for the power system.

As a result of the CDG feasibility work, on January 25, 1984, President Reagan, in his State of the Union message, gave NASA approval to build the Space Station and have it operational by 1994. In rapid succession a new program office was formed in Washington from the core Task Force group and the focus of the concept development activities was enlarged and shifted to the "Skunk Works" near the Johnson Space Center in Houston, Texas. The skunk works expanded and refined the definition of the Space Station Systems. They wrote a reference configuration description and a request for proposals for the next phase of the program. During this period, the importance of drag area on reboost cost and life-cycle cost coupled with the very large growth power requirements (as high as $450 \mathrm{kWe}$ ) resulted in the adoption of solar dynamic (SO) generators with thermal energy storage in addition to photovoltaic arrays with electrochemical energy storage for detailed study in the definition phase.

\section{DEFINITION PHASE}

The present Space Station configuration and the hybrid power system (Fig. 3) using both PV and SD technologies were selected in the definition or Phase B studies which began in 1984. Nuclear and other power systems were ruled out on the basis of schedule, cost, risk, and other factors. Because of the size and drag area of the power system, it is a major consideration for selection of the overall space station geometry. This geometry must allow the station and the power system to grow. It must minimize the impact of the power system on viewing angles for experimenters and for communications. The Space Station and its power system must be controllable and structurally sound. The maximum degree of commonality between the Station and platform power systems was necessary to reduce costs. Most important of all, the Station must be passively controllable, i.e., gravity gradient stabilized. From these diverse and sometimes contradictory requirements, the Power Tower and later the Dual Keel configurations were developed and studied by NASA. At the same time, the NASA Lewis Research Center, along with its two major Phase B Contractors, TRW and Rocketdyne studied numerous power system types. These Phase $B$ definition studies are described below.

\subsection{Power System Configuration Definition}

Early in Phase B, six scenarios or cases for power system options were defined for study (Fig. 4). The IOC power level of $75 \mathrm{kWe}$ and the growth power level of $300 \mathrm{kWe}$ were selected. The six cases were established on the basis of IOC power system type (either SD or PV), and the method of growing from 75 to $300 \mathrm{kWe}$. Case 1 was all PV. Case 6 had minimum PV ( $12.5 \mathrm{kWe})$ at IOC and all SO at growth. An all SD system is not feasible because power is needed on the first Taunch when accurate sun tracking required for the SD system is not possible. Cases 2 through 5 had various proportions of SD to PV. Commonality between the station and the platform solar arrays was also considered in these system studies. If a solar array is optimized for the platform, it would be smaller than one optimized for the station. As a cost saving measure, platform arrays could be used on the station so that only one development cost would be incurred. The use of SD on the platform was not 
feasible due to microgravity, weight, and other requirements. Also, there was an incompatibility in power level between platform requirements and a practical sized SD unit.

The primary selection criteria for these system studies was both IOC and life cycle cost for the station and the platforms. Development, manufacturing, verification testing, overhead, and launch costs for all the Space Station System hardware and software was included. An especially important life cycle cost savings resulted from the reduced aerodynamic drag associated with the SD system. This reduced drag allowed lower orbit altitude and higher shuttle payload capacity.

As a result of these system studies, the case 5 hybrid was selected. In this case, the PV portion of the power system generates $25 \mathrm{kWe}$ with four solar array wings (array power approximately $57 \mathrm{kWe})$. The station wing is identical in desian to those optimized for the platform. The station would also use nickel hydrogen batteries identical to those designed for the platform. This commonality of hardware results in design and development cost savings for the Space Station program.

The SD portion of the case 5 power system generates about $50 \mathrm{kWe}$. The exact size of each So unit will depend upon the PMAD system efficiency. The SO units will use either the Brayton or the Rankine system and an offset parabolic concentrator. The exact design will depend upon the results of ongoing preliminary design studies. The detailed trade studies which helped define the technologies of the case 5 hybrid that was selected are described briefly below. These trade studies occurred at about the same time as the system level studies previousiy described. Overall the technologies for the photovoltaic system are low risk, and space proven whereas the solar dynamic technologies offer reduced $\mathrm{drag}$ and cost.

\subsection{Photovoltaic System Technology Studies}

3.2.1 Solar Array. Several array concepts were evaluated during the Phase $B$ studies. They included planar arrays, simple flat mirror concentrators, cassegranian concentrators, and troughtype concentrators. Preliminary trade studies considered all known degradation factors including optical, electrical, mechanical, etc., effects. In addition, packing factors, pointing and structural requirements, number of components, drag area, costs and technology readiness were also considered. On the basis of these factors, a planar array with silicon cells was selected. A cassegranian array with gallium arsenide cells looked promising, but cell efficiencies of about 30 percent were required to compete with the planar silicon design. This cell efficiency is beyond that projected for production cells available at the start of the Space Station IOC array fabrication in 1988-1989.

The issue of deployable/erectable versus deployable/retractable arrays was also studied. Combinations of types of array substrate, masts, construction methods, on-orbit assembly methods, and means of integrating the substrate to the mast were devised for study. Masts considered included both articulated and continuous longeron types. Evaluation factors included complexity to build and test, cost, on-orbit (extra vechilar activity) assembly time, array retractability, mast stiffness, reliability, damage tolerance, repairability, atomic oxygen resistance, technology readiness, and other factors. When all these factors were considered, a planar, deployable, fold-out array with a coilable, continuous longeron mast was selected. The array wing design for the station and the platform will be the same. It will have two flexible blankets and a center mast. Each blanket will be stored in a containment box/cover assembly during 1aunch.

This array design is similar to the NASA Office of Aeronautics and Space Technology (OAST) flight experiment, OAST 1 (Fig. 5). This solar array flight experiment was performed on a Space Shuttle mission (STS 41D) launched in August 1984. A 13 by $105 \mathrm{ft}$ array consisting of 84 hinged panels was deployed and retracted on-orbit several times. The array blanket panels were flexible. The deployment mast was a coilable longeron type. This array was built by the Lockheed Missile and Space Company. To reduce cost, only three panels contained solar cells. If fully populated with cells, the array power output would be about 13 to $14 \mathrm{kWe}$ at the wing root.

The OAST 1 flight experiment was completely successful. It showed that the array was well behaved dynamically. Its performance in general was as predicted and the solar cells were not damaged during the mission. This flight experiment demonstrated that this array type is technology ready and established that space station planners can have a high degree of confidence in it. A more detailed description of the array and the flight experiment results $c$ an be found in Ref. 3 .

The OAST type array has several advantages compared with other array types. It is lighter in weight and packs in a small volume for launch. It has sufficient stiffness to meet Space Station structural and dynamic requirements. The flexible substrate is made from Kapton which is transparent to infrared radiation. This allows the solar cells to operate at a lower temperature and thus with higher power output per unit area.

A disadvantage of the OAST 1 type array is its need for protection from the atomic oxygen present at the Space Station altitude. The Kapton substrate and other components which contain epoxy (e.g., the mast longerons, the blanket hinge pins and containment box and several smaller components) are attacked by atomic oxyqen. These components, if unprotected, may have very limited lifetime. The Space Station Advanced Development Program (Ref. 4) is beginning a contract to demonstrate practical methods to protect the array. The primary emphas is will be on coatings that are resistant or inert to atomic oxygen attack. These coatings must also meet other array performance requirements and must be compatible with other parts of the space environment such as UV, radiation, micrometeoroids, etc. These coatings are being developed by the Space Station Advanced Development Materials community. The planned array protection contract will provide an engineering solution to the atomic oxygen problem.

It will demonstrate that the protection methods are compatible with array manufacturing and that they survive that process and still protect the array. The most critical need is for the Kapton blanket.

If suitable coatings cannot be demonstrated, alternate blanket approaches are possible. These approaches include laminating Kapton sheets over 
an inner layer of material that is resistant to atomic oxygen or using aluminum as the substrate. These approaches might result in higher weight and/or decreased cell power output due to loss of infrared transmission through the substrate.

3.2.2 Solar Cell. Detailed solar cell assembly design options that were studied include silicon versus gallium arsenide, base resistivity, back surface field (BSF), IR reflector versus transparent back contacts, conventional top-bottom, wrap-around, or wrap-through type contacts, cell size and thickness and cover glass material type and thickness. Evaluation criteria were IOC and life cycle cost, development status and performance achieved by 1988-1989 when array fabrication will begin.

The array design features selected were $N$ on $P$ silicon cells with $2 \Omega-c m$ base resistivity, 8 by $8 \mathrm{~cm}$ size, $8 \mathrm{mils}$ thick, IR transparent gridded back contacts, a BSF, and a wrap through front contact using a $6 \mathrm{mil}$ ceria-doped coverglass. The wrap-through front contact and the large cell size reduce array assembly time arid cost. The gridded back allows IR transmission through the array blanket resulting in higher array power output for a fixed area.

Silicon solar cells have been used on many spacecraft in the past. They have extensive operational, assembly and manufacturing experience. Although the selected cell is larger than those used previously, it is still a very low risk approach. The Space Station Advanced Development Program will demonstrate pilot production of these cells in early 1987. Efficiencies of 14 percent are expected.

3.2.3 Energy Storage System. The PV system will store energy electrochemicatiy. This stored energy is needed during the dark portion of the orbit and for contingency purposes when the power system cannot produce and/or deliver power. The Phase $B$ studies showed that the inherent storage capability or residual energy of the electrochemical system was adequate to meet expected contingency requirements. Building in greater contingency capability was unnecessarily expensive. Energy storage options studied included nickel-cadmium ( $\mathrm{NiCd}$ ) batteries, regenerative fuel cell (RFC), and nickel-hydrogen $\left(\mathrm{NiH}_{2}\right)$ batteries.

NiCd batteries are established, flight-proven, low-risk devices. However, their low depth of discharge results in high storage system weight. Space-type cells up to $100 \mathrm{~A}-\mathrm{hr}$ sizes have been produced so that development risk would be low.

The RFC uses a fuel cell and an electrolyzer to store energy in the form of hydrogen and oxygen. In the dark portion of the orbit, they are recombined in the fuel cell to produce water and electricity. During the lighted portion of the orbit, excess array power is used to electrolyze the water and "charge" the system with hydrogen and oxygen. The cycle is closed so that the fluids are not consumed. The RFC is lighter than batteries and allows storage of large amounts of contingency power with small changes in tank volume. However, the RFC is not as efficient as batteries (60 compared with 80 percent) so that the solar arrays must be larger. Also, the RFC is more complex (i.e., pumps, valves, etc.) and not as reliable as batteries. RFC's also have higher heat rejection needs. Reliability was a major consideration for the platform where 3 vears of operation without repair were required. However, commonality between the station and the platform to reduce development, resupply, and sparing costs was also considered.

The $\mathrm{NiH}_{2}$ battery has been used in geosynchronous (GEO) spacecraft (Fig. 6) in the individual pressure vessel (IPV) type.

(The bipolar $\mathrm{NiH}_{2}$ battery has low technology maturity and was screened out by the early trade studies). IPV, $3.5 \mathrm{in}$. diameter, 50 A-hr GEO-type cells are in production. Other sizes and capacities are available using scale-up of existing components. The uncertainty with the $\mathrm{NiH}_{2}$ battery stems from its charge-discharge cycle life. GEO spacecraft experience only a fraction of the cycles that a LEO spacecraft experiences. However the Space Station Advanced Development Program is beginning to test "LEO type" cells with a goal of demonstrating a minimum of 5 year lifetimes.

As a result of the Phase $B$ trade studies, IPV $\mathrm{NiH}_{2}$ batteries were selected for the platform. Weight, cost, reliability, development risk, and schedule were the primary considerations. They are about half the weight and lower in cost than NiCd batteries and more reliable than the RFC. An identical IPV $\mathrm{NiH}_{2}$ battery was also selected for the Station on the basis of cost and commonality with the platform. IPV NiHz was lower in IOC cost and only slightly higher in life-cycle cost for the Station.

\subsection{Solar Dynamic Technology Studies}

The solar dynamic system consists (Fig. 7) of an offset parabolic concentrator mirror which focuses the suns heat into a receiver. The receiver stores the heat in a salt (e.g., $\mathrm{LiOH}$ ) and also transfers it to a working fluid (e.g., toluene or heliumxenon gas). The heated fluid drives a turbine which spins an alternator to generate $A C$ electrical energy. The turbine also drives a pump which recirculates the working fluid. Excess heat is rejected to space by a radiator.

In the trade studies the two conversion cycles considered were closed Brayton cycle (CBC) and organic Rankine cycle (ORC). These systems have not been used in space, but a technology data base for the heat engines has resulted from terrestrial and aircraft applications. Estimating costs, schedules, and other factors during the Phase B trade studies was therefore higher risk than for the PV system.

Design considerations for the SD system studied in Phase $B$ and being worked in the Advanced Development Program include low gravity effects for two phase (gas-liquid) flow, heat flow and distribution in the receiver, lifetime for thermal energy storage (salt) capsules, weight and optical quality of the concentrator, pointing accuracy $\left(0.1^{\circ}\right)$ for the mirror gimbals, atomic oxygen protection, launch packaging, on-orbit assembly, and other factors.

At the time of this writing both the CBC and the ORC systems are still being considered. More detailed study is required because cost and performance are nearly identical. 


\subsection{Power Management and Distribution Studies}

The power management and distribution (PMAD) system must cope with load types and sizes that will be unknown as the station users change and increase in number. Therefore the PMAD system must be user friendly and adaptable to change and growth. The PMAD system for the Space Station must resemble a terrestrial utility-type power system rather than the PMAD system of previous spacecraft. Distribution voltages higher than the 28 volts previously used are mandatory to reduce loses.

During Phase $B$, distribution frequencies of $D C$, $400 \mathrm{~Hz} \mathrm{AC}$, and $20 \mathrm{KHz} \mathrm{AC}$ were studied. Component efficiency, size and weight as well as technology readiness, availability of space type components, acoustic noise, electromagnetic interference and plasma coupling were all considerations. After much consideration, $20 \mathrm{KHz}$ was selected for the PMAD distribution frequency.

The overall PMAD architecture selected is a dualring system with 15 kWe busses supplying power to 10 load areas on the upper and lower keels and the transverse boom. Busses supplying the manned modules are rated at $30 \mathrm{kWe}$. The PMAD system contains numerous switching assemblies and control assemblies as well as a control system for sensing and commanding the loads. Isolators and power controllers will sense faults and protect the system.

\section{SUMMARY}

The present Space Station program traces its roots back before the dawn of the space program. The station configuration and the power system for the present program has been studied extensively in the feasibility and definition phases.
The hybrid power system selected will meet the station and platform requirements initially and into the future. The $25 \mathrm{kWe} P V$ system ( $57 \mathrm{kWe}$ array power) will be larger than any system flown to date. The SD system will facilitate econornics and growth for the power system and the station. The PMAD system enables a growable, balanced utility-type system approach for maximum friend7 iness for the station users.

The technologies selected for PV, SD and PMAD result in the lowest IOC costs and life cycle costs with acceptable development and schedule risk. This hybrid system also meets programmatic and technical considerations driving the power system definition. The Space Station power system may set the standard for future spacecraft power systems.

\section{REFERENCES}

1. Hook, W.R., Space Stations - Historical Review and Current Plans. ASME Winter Meeting, Phoenix, AZ, Nov. 14-19, 1982.

2. Space Station Mission Synthes is Workshop, NASA Proceedings, Hampton, VA, March 5-8, 1984.

3. Solar Array Flight Experiment, Final Report. Lockheed Missles and Space Co., LMSC-F087173, Apr. 1986.

4. Forestieri, A.F., Baraona, C.R., and Valgora, M.E., Space Station Power System Advanced Development, 20th Intersociety Energy Conversion Engineering Conference, Miami Beach, FL, Aug. 18-25, 1985, Warrendale, PA, SAE, 1.9-1.16. 
Table 1

SPACE STATION SYSTEM POWER REQUIREMENTS

\begin{tabular}{|c|c|c|}
\hline Element & User power a verage & kWe peak \\
\hline Manned core & & \\
IOC & 75 & 100 \\
Growth & 300 & 350 \\
Platforms & & \\
Polar & 8 & 16 \\
IOC & 15 & 24 \\
Growth & & 6 \\
Co-orbiting & 6 & 23 \\
IOC & 23 & \\
Growth & &
\end{tabular}

Table 2

POWER SYSTEM MANAGEMENT/ENGINEERING CONSIDERATIONS

\begin{tabular}{|l|l|}
\hline Initial cost & Schedule \\
Life-cycle cost & Orbit altitude and decay \\
Development risk & Growth capability \\
Commonality & Contingency requirement \\
Weight & Load types and location \\
Maintainability & Logistics and sparing \\
Failure criteria & Orbital assembly and buildup \\
Safety & Interfaces \\
Verification & Lifetime
\end{tabular}




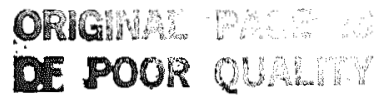

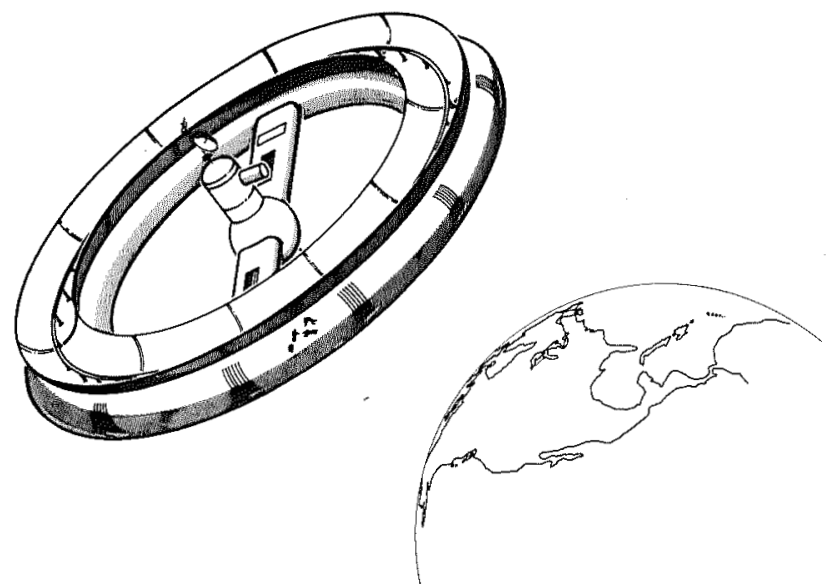

FIGURE 1. - A STATION IN SPACE: A 1952. CONCEPT.

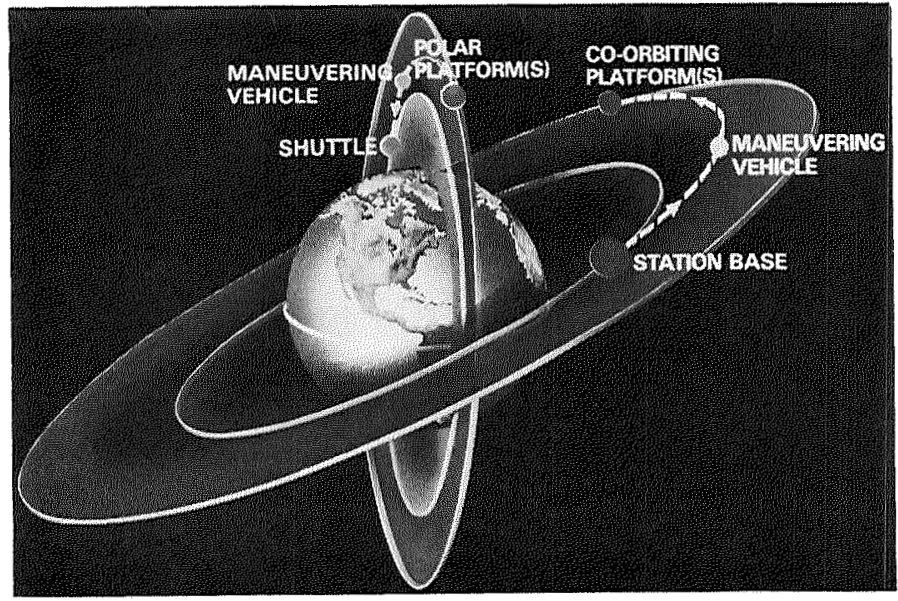

FIgURE 2. - SPACE STATION COMPLEX, EARLY $1990^{\circ} \mathrm{s}$. 


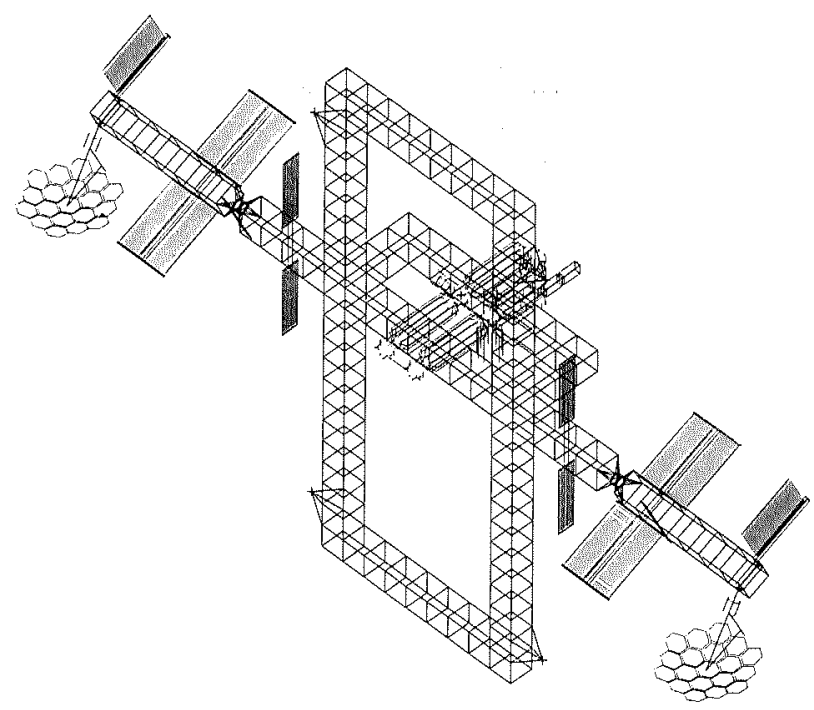

Figure 3. - Space station dual keel configuration 1986.

$I O C$

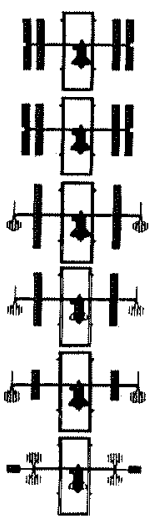

CASE

1. $\mathrm{IOC} P V$ GROWTH PV

2. IOC PV GROWTH SD

3. $\mathrm{IOC} 50 \mathrm{PV}-25 \mathrm{SD}$ GROWTH SD

4. IOC 37.5 PV-37.5 PD GROWTH SD

5. $10 C 25 \mathrm{PV}-50 \mathrm{SD}$ GROWTH SD

6. IOC $12.5 \mathrm{PV}-75 \mathrm{SD}$ GROWTH SD
GROWTH

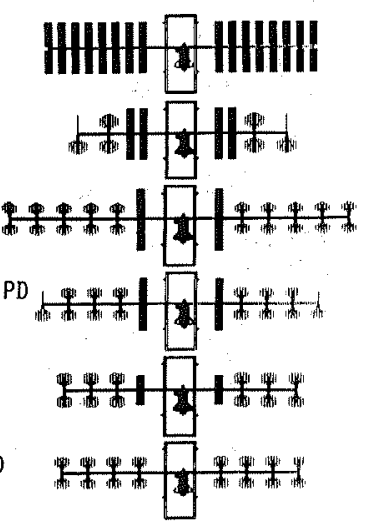

Figure 4. - CASEs evaluated for SPace Station power system. 


\section{ORGind \\ OF POOR QURHE.}

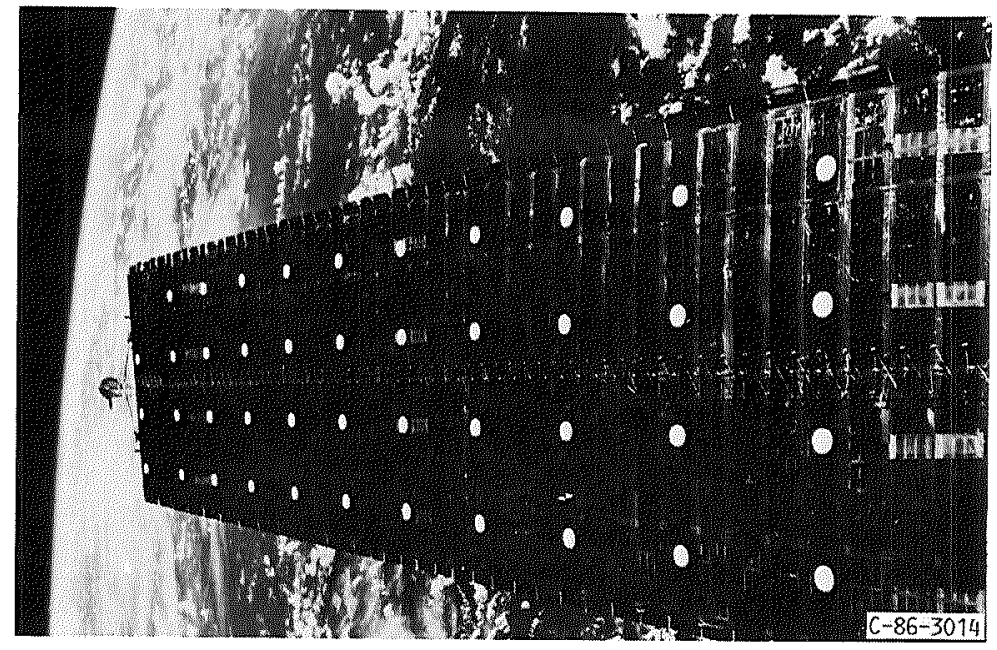

FIGURE 5. - OAST-1 SOLAR ARRAY FLIGHT EXPERIMENT, 1984.

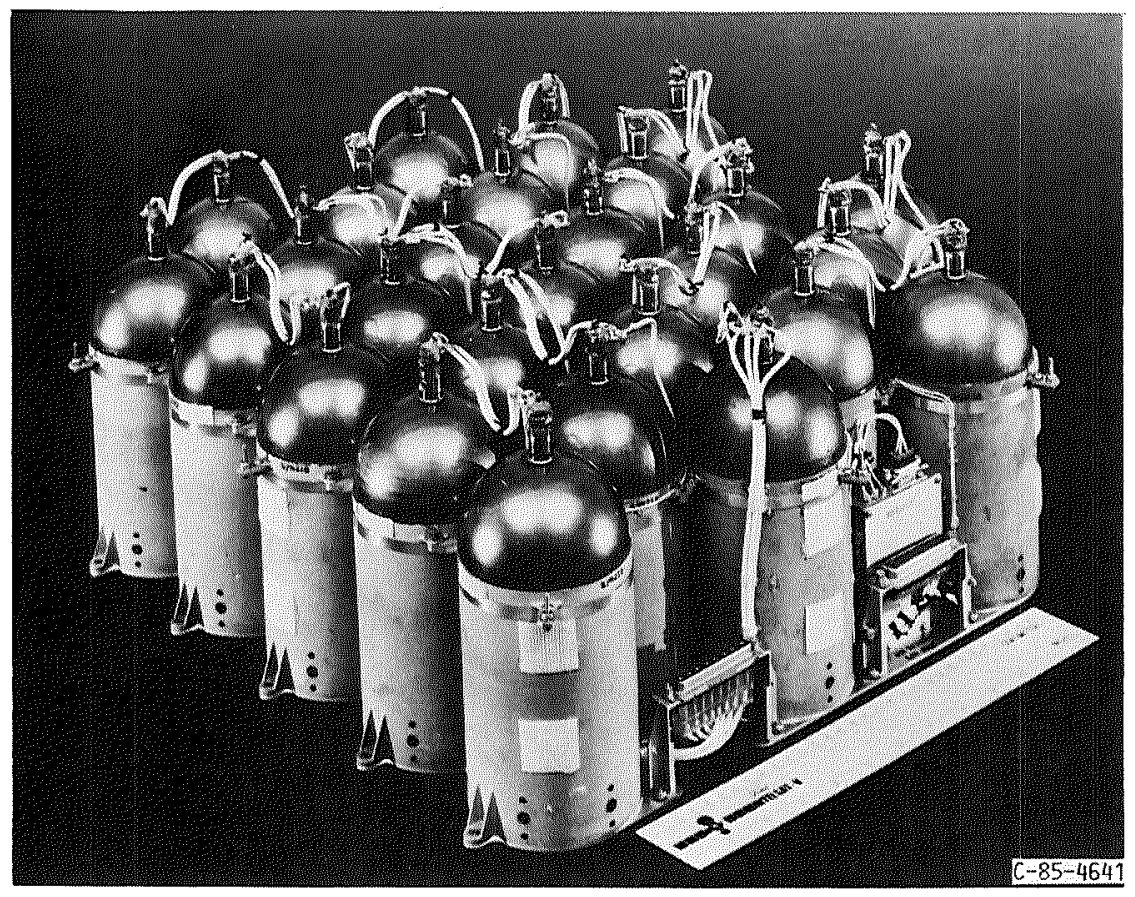

Figure 6. - INTELSAT V NICKEL HYDROGEN BATTERY. 


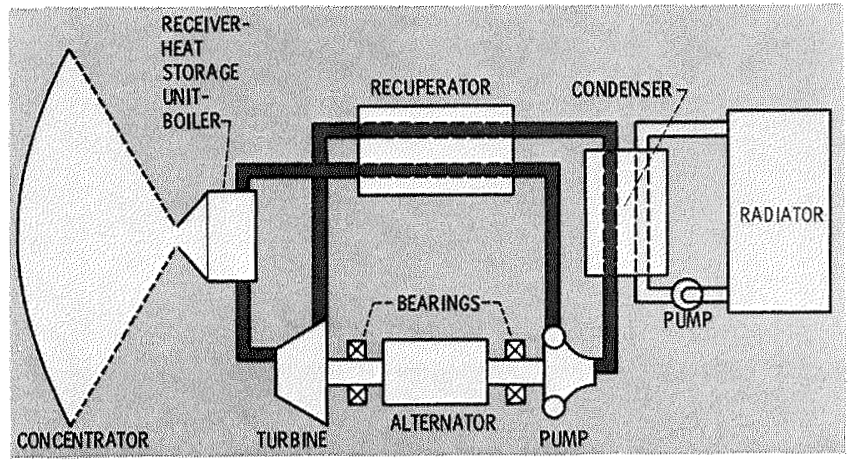

Figure 7. - Solar dYNamic sYSTEM SCHEMatic, organic Rank INE CYCle. 


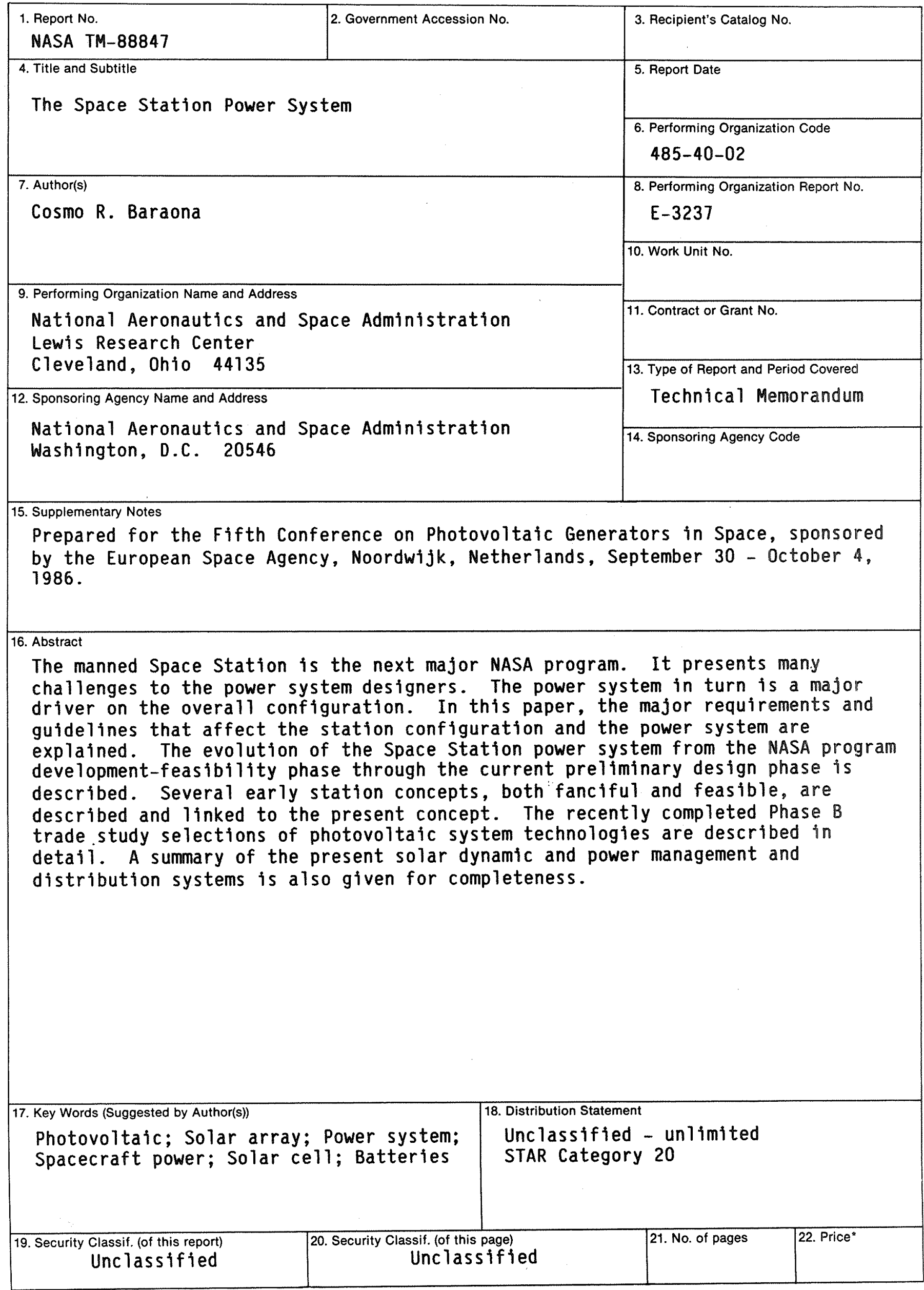

\footnotetext{
*For sale by the National Technical Information Service, Springfield, Virginia 22161
} 
National Aeronautics and

Space Administration

Lewis Flesearch Center

Cleveland. Ohio 44135

Onficial Business

Penaly for Privato Use $\$ 300$
SECOND CLASS MAIL

ADDRESS CORRECTION REQUESTED

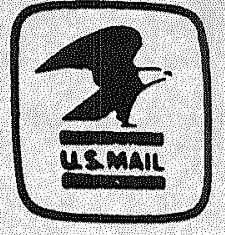

Postage and Fees Paid National Aeronautics and Space Administration NASA-451 